
$\mathrm{E}$, et al. Recovering Quality of Life (ReQoL): a new generic self-reported outcome measure for use with people experiencing mental health difficulties. Br J Psychiatry 2018; 212(1): 42-9.

31 Blenkiron $\mathrm{P}$, Hammill CA. What determines patients' satisfaction with their mental health care and quality of life? Postgrad Med J 2003; 79 (932): $337-40$
32 Van Sonderen $\mathrm{E}$, Middel B. Statistical significant change versus relevant or important change in (quasi) experimental design: some conceptual and methodological problems in estimating magnitude of interventionrelated change in health services research. Int J Integr Care 2002; 2: e15.

\title{
Factors influencing use of community treatment orders and quality of care that people receive: results of a national survey in England and Wales
}

\author{
Harry Lei, ${ }^{1}$ Kirsten Barnicot, ${ }^{1}$ [D Emily Maynard ${ }^{2}$ Angela Etherington, ${ }^{2}$ Krysia Zalewska, ${ }^{2}$ \\ Alan Quirk, ${ }^{2}$ Rahil Sanatinia, ${ }^{1}$ Stephen J. Cooper, ${ }^{2}$ Mike J. Crawford ${ }^{2}$
}

BJPsych Bulletin (2019) 43, 227-235, doi:10.1192/bjb.2019.23

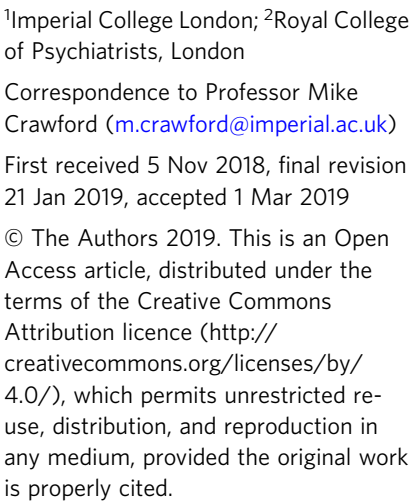

IImperial College London; ${ }^{2}$ Royal College of Psychiatrists, London

Correspondence to Professor Mike Crawford (m.crawford@imperial.ac.uk)

First received 5 Nov 2018, final revision 21 Jan 2019, accepted 1 Mar 2019

(c) The Authors 2019. This is an Open Access article, distributed under the terms of the Creative Commons Attribution licence (http:// creativecommons.org/licenses/by/ 4.0/), which permits unrestricted reuse, distribution, and reproduction in any medium, provided the original work is properly cited.

Aims and method We conducted a secondary analysis of data from the National Audit of Psychosis to identify factors associated with use of community treatment orders (CTOs) and assess the quality of care that people on CTOs receive.

Results Between 1.1 and $20.2 \%$ of patients in each trust were being treated on a CTO. Male gender, younger age, greater use of in-patient services, coexisting substance misuse and problems with cognition predicted use of CTOs. Patients on CTOs were more likely to be screened for physical health, have a current care plan, be given contact details for crisis support, and be offered cognitive-behavioural therapy.

Clinical implications CTOs appear to be used as a framework for delivering higher-quality care to people with more complex needs. High levels of variation in the use of CTOs indicate a need for better evidence about the effects of this approach to patient care.

\section{Declaration of interest None.}

Keywords Community treatment order; psychosis; community care; mental health act.
Community treatment orders (CTOs) were introduced in England and Wales in 2008, in an attempt to reduce the use of in-patient services for patients with poor adherence to their treatment. ${ }^{1-3}$ They require individuals with mental disorders who have been detained in hospital to adhere to treatment and supervision in the community. Non-compliance with CTOs may lead to revocation, where the patient is involuntarily admitted back into hospital for further treatment. The use of similar legislation to enforce community treatment also exists in other countries, including the USA, Australia and New Zealand. ${ }^{4,5}$

Although CTOs have been recommended as a method for improving adherence and patient safety, patients treated under CTOs feel more coerced. ${ }^{6}$ The use of CTOs has been much higher than was initially anticipated, ${ }^{7,8}$ and has increased considerably since they were first introduced. ${ }^{8,9}$ Concerns have been raised about greater use of compulsion amongst people from ethnic minority communities. ${ }^{10-12}$
Data submitted to NHS Digital in 2016 indicated that Black or Black British patients were almost nine times more likely to be treated on a CTO than White British patients. ${ }^{13}$ A systematic review of data from 38 studies of clinical practice in the UK, which compared the use of in-patient mental health services by different ethnic groups, found that Black patients were over four times more likely to be admitted to hospital on a compulsory basis than White patients. ${ }^{10}$ However, other studies have reported that associations between use of compulsory treatment and ethnicity may be reduced or eliminated when other sociodemographic and clinical factors are taken into account. ${ }^{14,15}$ To date, the influence of clinical and sociodemographic factors on the association between ethnicity and use of CTOs has not been examined.

There is considerable variation in the experiences of people treated under CTOs. ${ }^{6}$ Surveys of both patients and carers indicate that many believe their main aim is to try 
to force people to take regular mediation. ${ }^{6,16}$ It has been argued that use of CTOs can improve a person's mental health and quality of life, but negative findings of randomised trials ${ }^{17,18}$ and limited information about the quality of care that people actually receive have led to calls for further research in this area. ${ }^{11,19}$

The National Clinical Audit of Psychosis is a 10 year programme of work commissioned by the Healthcare Quality Improvement Partnership as part of the National Clinical Audit and Patient Outcomes Programme in England and Wales, which aims to improve the quality of care that people with psychosis receive. ${ }^{20}$ In the light of concerns about increasing use of CTOs, patient representatives from the Steering Committee that oversees this programme of work requested that data on use of CTOs be included in the third round of the audit. By collecting data on whether people in the audit were being treated using a CTO, we aimed to identify patient characteristics that predict use of CTOs in England and Wales and to explore the quality of care received by people who were treated under a CTO compared with those who were not.

\section{Method}

This study was based on a secondary analysis of data from the third round of the National Clinical Audit of Psychosis. ${ }^{21}$ Data for the audit were obtained from clinical records of patients between September and November 2017. The study population were patients aged 16 or over who had received care from a provider of National Health Service (NHS) mental health services for at least 12 months on a census date ( 1 July 2017). To take part in the audit a patient had to have a current ICD-10 diagnosis of psychotic disorder secondary to alcohol or substance abuse, schizophrenia, persistent delusional disorder, schizoaffective disorder or other non-organic or unspecified psychotic disorders made before the age of 60 and 12 months or longer before the census date. ${ }^{22}$

All providers of mental health services in England and Wales were helped to generate a random sample of eligible patients. The sample size for each trust was between 100 and 300 patients, depending on the size of the trust. ${ }^{22}$ For each selected patient, staff working in the trust extracted data from electronic and other patient records to complete a 49-item online data collection form. This form included questions on demographic factors (including age, gender and ethnicity), clinical factors (including whether the patient had received in-patient treatment during the previous 12 months and whether the patient was currently in remission), data on the physical and mental healthcare that the patient had received, and scores from the Health of the Nation Outcome Scales (HoNOS) completed during the previous 12 months. ${ }^{22}$ HoNOS is a clinician-rated outcome measure which assesses patients' difficulties in a variety of mental health domains during the 2 weeks leading up to the point of rating. Scores for each domain range from 0 (absent) to 4 (severe), with higher scores indicating greater impairment. ${ }^{23}$ Finally, we collected data from a single item that asked whether the patient was currently being treated on a CTO.

Prior to the start of the audit, the National Research Ethics Service and the Ethics and Confidentiality

\begin{tabular}{|c|c|c|c|c|c|}
\hline Table 1 & $\begin{array}{l}\text { Numbe } \\
\text { on a C }\end{array}$ & $\begin{array}{l}\text { and } F \\
D \text { in } E\end{array}$ & $\begin{array}{l}\text { ortion } \\
\text { and anc }\end{array}$ & $\begin{array}{l}\text { seople } \\
\text { Vales }\end{array}$ & h psychosis \\
\hline Area & $N$ & $\begin{array}{l}\text { On } \\
\text { CTO }\end{array}$ & $\begin{array}{l}\text { Not on } \\
\text { CTO }\end{array}$ & $\begin{array}{l}\% \text { on a } \\
\text { CTO }\end{array}$ & $95 \% \mathrm{Cl}$ \\
\hline Total & 8760 & 529 & 8231 & 6.04 & $(5.55-6.53)$ \\
\hline London & 1514 & 92 & 1422 & 6.08 & $(4.88-7.28)$ \\
\hline $\begin{array}{l}\text { North } \\
\text { East }\end{array}$ & 2140 & 135 & 2005 & 6.31 & $(5.28-7.33)$ \\
\hline $\begin{array}{l}\text { North } \\
\text { West }\end{array}$ & 1244 & 95 & 1149 & 7.64 & $(6.16-9.11)$ \\
\hline $\begin{array}{l}\text { South } \\
\text { East }\end{array}$ & 1973 & 113 & 1860 & 5.73 & $(4.71-6.75)$ \\
\hline $\begin{array}{l}\text { South } \\
\text { West }\end{array}$ & 1492 & 63 & 1429 & 4.22 & $(3.20-5.24)$ \\
\hline Wales & 397 & 31 & 366 & 7.81 & $(5.17-10.45)$ \\
\hline
\end{tabular}

Committee of the National Information Governance Board advised that formal ethical approval was not required for this quality improvement initiative. Approval for the secondary analysis of the data in this study was obtained from the Healthcare Quality Improvement Partnership prior to the start of data analysis.

\section{Data management and analysis}

We excluded data from people who were in-patients at the point when data were collected, because it was unclear whether or not such patients had been treated using a CTO prior to their admission. For this analysis, we extracted data from the audit on demographic, clinical and service factors, together with information about whether the patient was currently being treated using a CTO, and evaluated the association between CTO treatment and demographic, clinical and service provision factors. Among all patients being treated in the community, we calculated the proportion of people currently being treated on a CTO, together with $95 \%$ confidence intervals.

We used $\chi^{2}$ tests and Mann-Whitney $U$-tests to compare the demographic and clinical characteristics of patients treated under CTOs with those of patients who were not. We then used univariate ordinal logistic regression to compare HoNOS ratings between patients who were treated under CTOs and those who were not. Demographic and clinical variables identified as differing significantly between patients treated under CTOs and others $(P<0.05)$ were then entered into a multivariate logistic regression in order to determine which variables were independently associated with a greater likelihood of treatment under a CTO. The multivariate logistic regression used multilevel modelling with a random effect for NHS trust in order to adjust for differences between NHS trusts in frequency of CTO usage.

Differences in service provision between patients who were treated under a CTO and those who were not were examined using multilevel logistic regression, adjusting for potential demographic and clinical confounders (age, sex, ethnicity, in-patient psychiatric hospital admission in the past 12 months), and including a random effect for patients' NHS trust in order to adjust for differences between NHS trusts 
Table 2 Comparison of demographic and clinical characteristics of patients treated and not treated on a CTO

\begin{tabular}{|c|c|c|c|c|c|}
\hline \multirow[b]{2}{*}{ Variable } & \multicolumn{2}{|c|}{ Treated on СТO } & \multicolumn{2}{|c|}{ Not treated on СТO } & \multirow[b]{2}{*}{$P$-value $\left(Z\right.$ or $\left.\chi^{2}\right)$} \\
\hline & Mean/n & $\%$ & Mean/n & $\%$ & \\
\hline Mean age in years (s.d.) & 44.05 & 11.51 & 46.84 & 11.35 & $<0.001^{\star}(5.450)$ \\
\hline Gender & & & & & $0.013^{\star}(8.733)$ \\
\hline Male & 367 & 69.38 & 5334 & 64.80 & \\
\hline Female & 161 & 30.43 & 2895 & 35.17 & \\
\hline Other/undefined & 1 & 0.19 & 2 & 0.02 & \\
\hline Ethnicity & & & & & $0.001^{\star}(19.910)$ \\
\hline White & 399 & 75.43 & 6454 & 78.41 & \\
\hline Black or Black British & 71 & 13.42 & 717 & 8.71 & \\
\hline Asian or British Asian & 26 & 4.91 & 640 & 7.78 & \\
\hline Mixed & 17 & 3.21 & 192 & 2.33 & \\
\hline Other ethnic groups & 16 & 3.02 & 228 & 2.77 & \\
\hline Diagnosis & & & & & $<0.001^{\star}(19.914)$ \\
\hline F10-19 Substance-induced & 17 & 3.21 & 230 & 2.79 & \\
\hline F20 Schizophrenia & 368 & 69.57 & 5946 & 72.24 & \\
\hline F25 Schizoaffective disorder & 118 & 22.31 & 1341 & 16.29 & \\
\hline F22, F24, F28, F29 Other & 26 & 4.91 & 714 & 8.68 & \\
\hline Time since diagnosis & & & & & $0.654(0.201)$ \\
\hline Less than 3 years & 103 & 19.47 & 1538 & 18.69 & \\
\hline 3 years or longer & 426 & 80.53 & 6693 & 81.31 & \\
\hline Current mental health & & & & & $<0.001^{\star}(63.464)$ \\
\hline Full remission & 81 & 15.31 & 2088 & 25.37 & \\
\hline Partial remission - minimal symptoms & 255 & 48.20 & 4258 & 51.73 & \\
\hline Partial remission - substantial symptoms & 165 & 31.19 & 1529 & 18.58 & \\
\hline Not in remission & 28 & 5.29 & 356 & 4.33 & \\
\hline Alcohol consumption & & & & & $0.852(0.035)$ \\
\hline Harmful use & 67 & 29.26 & 875 & 28.68 & \\
\hline No harmful use & 162 & 70.74 & 2176 & 71.32 & \\
\hline Substance misuse & & & & & $<0.001^{\star}(96.656)$ \\
\hline Yes & 159 & 33.40 & 1229 & 17.46 & \\
\hline No & 317 & 66.60 & 5810 & 82.54 & \\
\hline Use of in-patient services & & & & & $<0.001^{\star}(391.357)$ \\
\hline Admitted in past 12 months & 224 & 42.3 & 975 & 11.9 & \\
\hline No admission & 305 & 57.7 & 7526 & 88.2 & \\
\hline
\end{tabular}

* $P<0.05$.

in service provision. We compared 15 aspects of the quality of physical and mental healthcare that people received: whether the patient was prescribed a single antipsychotic drug; whether the current daily dose of antipsychotic medication was within the upper limits recommended in the British National Formulary; ${ }^{24}$ whether the patient had ever been offered cognitive-behavioural therapy for psychosis (CBTp); whether patients in contact with their families had been offered family intervention; whether the patient had been screened for smoking, harmful alcohol use, and substance misuse; whether interventions were offered for smoking cessation, or alcohol or substance use to those requiring them; whether the patient had a current care plan; whether there was documented evidence that the patient had been given information about how to contact healthcare services if in crisis; whether the patient had been offered support to obtain employment; and whether or not there was documented evidence that any identified carer had been offered an assessment of their needs.

All statistical analysis was carried out using SPSS version 21 or Stata SE version $14.2 .^{25,26}$

\section{Results}

All 62 trusts and health boards in England and Wales took part in the audit. Data were collected from 9449 patients, 
Table 3 HONOS scores of 5960 patients according to whether treated on a CTO

\begin{tabular}{|c|c|c|c|c|c|c|}
\hline HONOS item & Score & $\begin{array}{c}\text { On a CTO } \\
N=347 \\
n(\%)\end{array}$ & $\begin{array}{c}\text { Not on a CTO } \\
N=5613 \\
n(\%)\end{array}$ & Odds ratio & $95 \% \mathrm{Cl}$ & $P$-value \\
\hline \multirow[t]{5}{*}{ Overactive, aggressive, disruptive or agitated behaviour } & 0 & 130 (37) & 3062 (55) & 1.98 & $1.63-2.41$ & $<0.001$ \\
\hline & 1 & $99(29)$ & $1382(25)$ & & & \\
\hline & 2 & $80(23)$ & $810(14)$ & & & \\
\hline & 3 & $25(7)$ & $301(5)$ & & & \\
\hline & 4 & $13(4)$ & $58(1)$ & & & \\
\hline \multirow[t]{5}{*}{ Non-accidental self-injury } & 0 & $298(86)$ & $4820(86)$ & 1.03 & $0.76-1.41$ & 0.834 \\
\hline & 1 & $23(7)$ & $474(8)$ & & & \\
\hline & 2 & $15(4)$ & $201(4)$ & & & \\
\hline & 3 & $8(2)$ & $91(1.5)$ & & & \\
\hline & 4 & $2(1)$ & $24(0.5)$ & & & \\
\hline \multirow[t]{5}{*}{ Problem drinking or drug-taking } & 0 & $192(55)$ & $3897(69)$ & 1.85 & $1.50-2.28$ & $<0.001$ \\
\hline & 1 & $44(13)$ & $627(11)$ & & & \\
\hline & 2 & $54(16)$ & $523(9)$ & & & \\
\hline & 3 & $40(11)$ & $412(7)$ & & & \\
\hline & 4 & $16(5)$ & $135(2)$ & & & \\
\hline \multirow[t]{5}{*}{ Cognitive problems } & 0 & $148(43)$ & $2934(52)$ & 1.52 & $1.25-1.86$ & $<0.001$ \\
\hline & 1 & $91(26)$ & $1432(26)$ & & & \\
\hline & 2 & $76(22)$ & $904(16)$ & & & \\
\hline & 3 & $29(8)$ & $287(5)$ & & & \\
\hline & 4 & $3(1)$ & $49(1)$ & & & \\
\hline \multirow[t]{5}{*}{ Physical illness or disability problems } & 0 & $164(47)$ & $2448(44)$ & 0.88 & $0.72-1.07$ & 0.192 \\
\hline & 1 & $72(21)$ & $1227(22)$ & & & \\
\hline & 2 & $70(20)$ & $1168(21)$ & & & \\
\hline & 3 & $35(10)$ & $620(11)$ & & & \\
\hline & 4 & $6(2)$ & $134(2)$ & & & \\
\hline \multirow[t]{5}{*}{ Problems associated with hallucinations and delusions } & 0 & $54(16)$ & $1453(26)$ & 1.92 & $1.60-2.34$ & $<0.001$ \\
\hline & 1 & $68(20)$ & $1156(21)$ & & & \\
\hline & 2 & $97(28)$ & $1782(32)$ & & & \\
\hline & 3 & $90(26)$ & $975(17)$ & & & \\
\hline & 4 & $36(10)$ & $231(4)$ & & & \\
\hline \multirow[t]{5}{*}{ Problems with depressed mood } & 0 & $133(39)$ & $2235(40)$ & 1.01 & $0.83-1.23$ & 0.923 \\
\hline & 1 & $112(32)$ & $1731(31)$ & & & \\
\hline & 2 & $79(23)$ & $1251(22)$ & & & \\
\hline & 3 & $17(5)$ & $355(6)$ & & & \\
\hline & 4 & $3(1)$ & $34(1)$ & & & \\
\hline \multirow[t]{5}{*}{ Other mental and behavioural problems } & 0 & $97(28)$ & $1700(30)$ & 1.07 & $0.88-1.30$ & 0.496 \\
\hline & 1 & $71(21)$ & $1063(19)$ & & & \\
\hline & 2 & $98(29)$ & $1655(30)$ & & & \\
\hline & 3 & $60(17)$ & 1005 (18) & & & \\
\hline & 4 & $16(5)$ & $167(3)$ & & & \\
\hline \multirow[t]{5}{*}{ Problems with relationships } & 0 & $67(19)$ & $1835(33)$ & 2.08 & $1.71-2.53$ & $<0.001$ \\
\hline & 1 & $78(23)$ & $1452(26)$ & & & \\
\hline & 2 & $101(29)$ & $1458(26)$ & & & \\
\hline & 3 & $83(24)$ & $739(13)$ & & & \\
\hline & 4 & $16(5)$ & $113(2)$ & & & \\
\hline
\end{tabular}




\begin{tabular}{|c|c|c|c|c|c|c|}
\hline HONOS item & Score & $\begin{array}{c}\text { On a CTO } \\
N=347 \\
n(\%)\end{array}$ & $\begin{array}{c}\text { Not on a CTO } \\
N=5613 \\
n(\%)\end{array}$ & Odds ratio & $95 \% \mathrm{Cl}$ & $P$-value \\
\hline \multirow[t]{5}{*}{ Problems with activities of daily living } & 0 & $86(25)$ & $1845(33)$ & \multirow[t]{5}{*}{1.43} & \multirow[t]{5}{*}{$1.18-1.73$} & \multirow[t]{5}{*}{$<0.001$} \\
\hline & 1 & $80(23)$ & $1366(24)$ & & & \\
\hline & 2 & $108(31)$ & $1,513(27)$ & & & \\
\hline & 3 & $60(18)$ & $762(14)$ & & & \\
\hline & 4 & $10(3)$ & $120(2)$ & & & \\
\hline \multirow[t]{5}{*}{ Problems with living conditions } & 0 & $188(55)$ & $3633(65)$ & \multirow[t]{5}{*}{1.58} & \multirow[t]{5}{*}{$1.28-1.95$} & \multirow[t]{5}{*}{$<0.001$} \\
\hline & 1 & $72(21)$ & $973(17)$ & & & \\
\hline & 2 & $44(13)$ & $622(11)$ & & & \\
\hline & 3 & $29(8)$ & $269(5)$ & & & \\
\hline & 4 & $12(3)$ & $91(2)$ & & & \\
\hline \multirow[t]{5}{*}{ Problems with occupation and activities } & 0 & $99(29)$ & $2063(37)$ & \multirow[t]{5}{*}{1.47} & \multirow[t]{5}{*}{$1.21-1.79$} & \multirow[t]{5}{*}{$<0.001$} \\
\hline & 1 & $74(22)$ & $1246(22)$ & & & \\
\hline & 2 & $97(28)$ & $1426(25)$ & & & \\
\hline & 3 & $60(17)$ & $706(13)$ & & & \\
\hline & 4 & $15(4)$ & $153(3)$ & & & \\
\hline
\end{tabular}

of whom 8760 patients were being treated in the community and were therefore eligible for this study. Table 1 lists the frequency of use of CTOs at a national and regional level. Across England and Wales, 6.04\% $(n=529)$ of patients were being treated on a CTO at the time of the audit. The proportion of people being treated on a CTO was highest in Wales and lowest in the South West of England. There was also considerable variation in use of CTOs among patients treated across the 62 trusts and health boards, ranging from 1.06 to $20.22 \%$.

\section{Predictors of use of CTOs}

Demographic and clinical characteristics of patients who were and were not treated under a CTO are presented in Table 2, and HoNOS scores of the two groups are presented in Table 3. Among the 6853 White British patients, 399 (5.82\%) were currently being treated on a CTO; among the 788 patients whose ethnicity was recorded as Black or Black British, $71(9.02 \%)$ were currently being treated on a CTO. Scores on all but four HoNOS items were higher among those treated on a CTO compared to those who were not. Differences in the use of CTOs across trusts explained 5.0\% of the overall variance in use of CTOs (95\% C.I. 2.70-8.77). In the multivariate multilevel model using a random effect for NHS trust, the variables significantly independently predicting a greater likelihood of CTO use were: younger age, male gender, psychiatric hospital admission in the past 12 months, current substance misuse, and greater levels of cognitive problems on the HoNOS (Table 4).

\section{Quality of care delivered to patients on CTOs}

Data on the quality of care provided to patients who were and were not being treated on a CTO are presented in
Table 5. After adjusting for age, sex, ethnicity and history of in-patient psychiatric hospital admission in the past 12 months, patients treated on a CTO were more likely to be screened for smoking and substance misuse, have a current care plan, have documented evidence of being given contact details to be used in a crisis, and be offered CBTp.

\section{Discussion}

The results of this study suggest that, in England and Wales, age, gender, coexisting substance misuse and problems with cognition predict whether people are treated on a CTO. Previous studies have reported higher rates of substance misuse among people who are treated in the community on a compulsory basis. ${ }^{27}$ People who have substance misuse problems in addition to psychosis are more likely to relapse and more likely to be admitted to hospital. ${ }^{28,29}$ Data from this study suggest that clinicians use CTOs to provide a framework for trying to mitigate against these risks.

By contrast, previous studies of compulsory community treatment have not examined the influence of cognitive impairment on the use of CTOs. Problems with cognition are defined in the HoNOS as 'problems of memory, orientation and understanding associated with any disorder: learning disability, dementia, schizophrenia'. ${ }^{23}$ We did not collect data on whether people in the audit had other coexisting mental health conditions. However, whether the higher levels of cognitive problems rated on the HoNOS among those treated on CTOs resulted from coexisting intellectual impairment or were directly associated with their psychosis, ${ }^{30}$ it seems that clinicians are more likely to use CTOs when patients with psychosis also have difficulties with making decisions and organising their lives. Surveys of clinicians in both the UK and New Zealand indicate that the most important role of CTOs is ensuring that patients maintain 


\begin{tabular}{|c|c|c|c|}
\hline Independent variable ${ }^{a}$ & Odds ratio & $95 \% \mathrm{Cl}$ & $P$-value \\
\hline Age & 0.98 & $0.96-1.00$ & 0.049 \\
\hline Gender: Male & 1 & - & - \\
\hline Female & 0.48 & $0.28-0.80$ & 0.005 \\
\hline Ethnicity: White & 1 & - & - \\
\hline Black or Black British & 1.35 & $0.77-2.36$ & 0.297 \\
\hline Asian or British Asian & 0.76 & $0.28-2.04$ & 0.587 \\
\hline Mixed & 0.99 & $0.36-2.75$ & 0.983 \\
\hline Other ethnic groups & 1.82 & $0.52-6.35$ & 0.347 \\
\hline Diagnosis: Other psychoses & 1 & - & - \\
\hline Schizophrenia & 1.06 & $0.68-1.65$ & 0.790 \\
\hline Mental health: Partial/ no remission & 1 & - & \\
\hline Full remission & 0.68 & $0.38-1.22$ & 0.203 \\
\hline Harmful alcohol consumption: No & 1 & - & - \\
\hline Yes & 0.74 & $0.47-1.16$ & 0.186 \\
\hline Substance misuse: No & 1 & - & - \\
\hline Yes & 1.98 & $1.28-3.05$ & 0.002 \\
\hline Psychiatric hospital admission: No & 1 & - & - \\
\hline Yes & 4.57 & $3.07-6.79$ & $<0.001$ \\
\hline HONOS Overactive, aggressive, behaviour & 1.05 & $0.85-1.28$ & 0.661 \\
\hline HONOS Problem drinking or drug-taking & 0.93 & $0.78-1.10$ & 0.388 \\
\hline HONOS Cognitive problems & 1.28 & $1.04-1.57$ & 0.021 \\
\hline HONOS Problems with hallucinations and delusions & 1.08 & $0.90-1.30$ & 0.397 \\
\hline HONOS Problems with relationships & 1.21 & $1.02-2.08$ & 0.080 \\
\hline HONOS Problems with activities of daily living & 0.94 & $0.75-1.18$ & 0.597 \\
\hline HONOS Problems with living conditions & 1.07 & $0.88-1.30$ & 0.484 \\
\hline HONOS Problems with occupation and activities & 0.93 & $0.77-1.14$ & 0.509 \\
\hline
\end{tabular}

a. Adjusted for NHS trust.

their contact with mental health services. ${ }^{31,32}$ Clinical teams may judge that the power of recall helps ensure that people with psychosis who have impaired cognition maintain their contact with services.

We did not find evidence that ethnicity was an independent predictor of the use of CTOs. While Black and Black British patients were $55 \%$ more likely to be treated on a CTO than White British patients, differences in the adjusted odds of being treated on a CTOs among ethnic groups were not statistically significant. Nor did we find evidence that other aspects of mental state, including suicidal behaviour or problems associated with hallucinations and delusions, predicted use of CTOs.

\section{Study strengths and limitations}

The main strength of this study is that we were able to analyse data on patients from all trusts in England and Wales, which means that we can be confident that these findings are generalisable across the country. Another strength is that there was little missing data. The items with the largest amount of missing data were scores on the HoNOS, but even these scores were available for $70 \%$ of study patients. The inclusion of HoNOS data was important as it enabled us to examine whether demographic factors truly influence the use of CTOs once the potentially confounding effects of clinical variables have been taken into account.

The main limitation of the study is the reliance on data which were retrospectively extracted from patient records. This means that if interventions were delivered but not documented, these would not have been included in our analysis. Various steps were taken to maximise the reliability of data gathered in the audit, including piloting the data collection tool during an earlier round of the audit and providing comprehensive guideline notes for those tasked with extracting and entering data on the audit's online data management platform. Although questions have been raised about the reliability of HoNOS, ${ }^{33}$ it remains the only outcome measure in widespread use in the UK and therefore provides a valuable source of routine data on the health and social functioning of people who use secondary care mental health services. ${ }^{34,35}$ We were able to analyse data from a large sample of over 8000 patients. However, the relatively small numbers of patients on a CTO meant that we had limited power to examine differences in use of CTOs among some groups of patients. Although we are only able to report on 
Table 5 Descriptive statistics and logistic regression comparing quality of care received by patients on a CTO and those who were not

\begin{tabular}{|c|c|c|c|c|c|c|c|}
\hline \multirow[b]{2}{*}{ Aspect of care ${ }^{a}$} & \multicolumn{2}{|c|}{$\begin{array}{l}\text { On CTO } \\
N=529\end{array}$} & \multicolumn{2}{|c|}{$\begin{array}{c}\text { Not on CTO } \\
\quad N=8231\end{array}$} & \multirow[b]{2}{*}{ Odds ratio } & \multirow[b]{2}{*}{$95 \% \mathrm{Cl}$} & \multirow[b]{2}{*}{$P$-value } \\
\hline & $n$ & $\%$ & $n$ & $\%$ & & & \\
\hline Was screening for smoking carried out? & & & & & 1.61 & $1.14-2.30$ & 0.008 \\
\hline Yes & 490 & 92.63 & 7114 & 86.43 & & & \\
\hline No & 37 & 7.37 & 1117 & 13.57 & & & \\
\hline Was screening for alcohol misuse carried out? & & & & & 1.35 & $0.95-1.93$ & 0.096 \\
\hline Yes & 490 & 92.63 & 7261 & 88.22 & & & \\
\hline No & 39 & 7.37 & 970 & 11.78 & & & \\
\hline Was screening for substance misuse carried out? & & & & & 1.49 & $1.03-2.15$ & 0.032 \\
\hline Yes & 493 & 93.19 & 7203 & 87.51 & & & \\
\hline No & 36 & 6.81 & 1028 & 12.49 & & & \\
\hline Was intervention for smoking offered if needed? ${ }^{b}$ & & & & & 1.30 & $0.94-1.80$ & 0.108 \\
\hline Offered & 272 & 81.19 & 3060 & 78.7 & & & \\
\hline Not offered & 63 & 18.81 & 830 & 21.34 & & & \\
\hline Was intervention for alcohol offered if needed? ${ }^{b}$ & & & & & 1.00 & $0.41-2.44$ & 0.999 \\
\hline Offered $^{c}$ & 60 & 89.55 & 775 & 88.57 & & & \\
\hline Not offered & 7 & 10.45 & 100 & 11.43 & & & \\
\hline Was intervention for substance misuse offered? ${ }^{b}$ & & & & & 1.05 & $0.64-1.74$ & 0.834 \\
\hline Offered $^{c}$ & 133 & 83.65 & 1022 & 83.16 & & & \\
\hline Not offered & 26 & 16.35 & 207 & 16.84 & & & \\
\hline Polypharmacy being used & & & & & 0.84 & $0.65-1.08$ & 0.163 \\
\hline Yes & 82 & 15.59 & 1440 & 18.22 & & & \\
\hline No & 444 & 84.41 & 6464 & 81.78 & & & \\
\hline Total antipsychotic drug dose above BNF maxima & & & & & 0.79 & $0.54-1.16$ & 0.228 \\
\hline Yes & 32 & 6.08 & 573 & 7.25 & & & \\
\hline No & 494 & 93.92 & 7331 & 92.75 & & & \\
\hline Evidence of patient involvement in deciding antipsychotic medication & & & & & 1.05 & $0.86-1.28$ & 0.648 \\
\hline Yes & 351 & 66.73 & 5181 & 65.55 & & & \\
\hline No & 175 & 33.27 & 2723 & 34.45 & & & \\
\hline Current care plan & & & & & 2.97 & $1.71-5.18$ & $<0.001$ \\
\hline Yes & 514 & 97.16 & 7597 & 92.30 & & & \\
\hline No & 15 & 2.84 & 634 & 7.70 & & & \\
\hline Crisis contact details provided & & & & & 1.62 & $1.15-2.26$ & 0.005 \\
\hline Yes & 484 & 91.49 & 7183 & 87.27 & & & \\
\hline No & 45 & 8.51 & 1048 & 12.73 & & & \\
\hline Offered CBTp? & & & & & 1.27 & $1.03-1.56$ & 0.026 \\
\hline Yes & 168 & 31.76 & 2144 & 26.05 & & & \\
\hline No & 361 & 68.24 & 6087 & 73.95 & & & \\
\hline Offered family intervention $^{\mathrm{d}}$ & & & & & 1.24 & $0.86-1.78$ & 0.248 \\
\hline Yes & 66 & 39.76 & 796 & 32.77 & & & \\
\hline No & 100 & 60.24 & 1633 & 67.23 & & & \\
\hline Offered work support programme ${ }^{\mathrm{e}}$ & & & & & 0.53 & $0.16-1.83$ & 0.317 \\
\hline Yes & 12 & 63.16 & 242 & 76.34 & & & \\
\hline No & 7 & 36.84 & 75 & 23.66 & & & \\
\hline Evidence that carer's needs were assessed ${ }^{f}$ & & & & & 1.30 & $0.98-1.74$ & 0.073 \\
\hline
\end{tabular}




\begin{tabular}{|c|c|c|c|c|c|c|c|}
\hline \multirow[b]{2}{*}{ Aspect of care ${ }^{a}$} & \multicolumn{2}{|c|}{$\begin{array}{l}\text { On CTO } \\
N=529\end{array}$} & \multicolumn{2}{|c|}{$\begin{array}{c}\text { Not on CTO } \\
N=8231\end{array}$} & \multirow[b]{2}{*}{ Odds ratio } & \multirow[b]{2}{*}{$95 \% \mathrm{Cl}$} & \multirow[b]{2}{*}{$P$-value } \\
\hline & $n$ & $\%$ & $n$ & $\%$ & & & \\
\hline Yes & 145 & 61.97 & 1987 & 54.02 & & & \\
\hline No & 89 & 38.03 & 1691 & 45.98 & & & \\
\hline
\end{tabular}

a. All associations adjusted for age, gender, ethnicity, hospital admission in the past 12 months and NHS trust.

b. Based on subsample of 4225 individuals recorded as current smokers, 942 were identified as current hazardous drinkers and 1388 were identified as having a current substance misuse problem.

c. Of the 3332 smokers offered a smoking intervention, 1508 refused this (45.26\%); of the 835 hazardous drinkers offered an alcohol intervention, 186 refused this (19.75\%); of the 1155 substance abusing individuals offered an intervention, 288 refused this (20.75\%).

d. Based on subsample of $n=2595$ cases where the patient was in contact with their family and allowed the clinical team to contact them, and where a family therapist was available and family intervention had not been deemed inappropriate for the patient.

e. Based on subsample of 336 cases where it was documented that the patient was seeking work.

f. Based on subsample of 3912 cases where it was documented that the patient had a carer.

the use of CTOs among people with schizophrenia and related psychoses, most people treated using a CTO have psychosis. It is important that future research examine factors that influence the use of CTOs among all those who may be treated under them, including people with intellectual disability.

\section{Implications of study findings}

The results of this study provide some assurance about the quality of care that people treated using CTOs in England and Wales receive. Rather than simply being a means to encourage adherence to medication or attend follow-up appointments, people on CTOs in this study were more likely to be referred for psychological therapy and to have documented evidence of care plans and assessment of their physical health. Although many patients treated under CTOs believe that they are used to enforce use of medication, ${ }^{6}$ the results of this study indicate that people on CTOs may be receiving better quality of care overall. Nonetheless, it is important to note that even among people on CTOs, standards of care, especially in relation to psychological treatments and physical health assessment, fall below recommended standards. ${ }^{36}$

Arguably the most important finding in this study is the high degree of variation in use of CTOs across different trusts and in different parts of the country. CTOs represent a significant limitation on the rights of patients, and the high level of variation is therefore of concern. ${ }^{12}$ There are a number of possible explanations for this variation. These include random variation resulting from study sampling, differences in the populations served by different trusts and differences in the organisation and delivery of local services. Trevithick and colleagues noted that trusts serving large urban centres have higher rates of CTO use. ${ }^{8}$ Studies have also shown that there are higher rates of CTO use in trusts that provide specialist services for people with intellectual disability. ${ }^{8,31}$

Another reason for differences in levels of use of CTOs in different parts of the country could be continuing uncertainty about the clinical effectiveness of this approach to helping people with psychosis. While the results of the OCTET trial and other randomised trials of compulsory community treatment suggest that CTOs do not reduce use of in-patient services or lead to improved mental health or quality of life, ${ }^{17,18}$ questions have been raised about whether the results of these trials can be generalised to routine clinical settings ${ }^{37}$ and many psychiatrists remain convinced of their benefit. It seems likely, given this degree of uncertainty, that the extent to which different teams use CTOs is influenced by the opinions and experiences of clinicians who are responsible for delivering patient care.

\section{Conclusions}

The findings of this study suggest that, in addition to marked variation at the trust level, male gender, younger age, coexisting substance misuse and problems with cognition influence the use of CTOs in England and Wales. Patients treated on CTOs appear to be receiving higher quality of care than those who are treated on a voluntary basis These results highlight the need for further research into the costs and benefits of treating patients using CTOs so that unwarranted variation in their use can be minimised.

\section{Funding}

The National Clinical Audit of Psychosis is managed by the Royal College of Psychiatrists' College Centre for Quality Improvement. It is commissioned by the Healthcare Quality Improvement Partnership as part of the National Clinical Audit and Patient Outcomes Programme. The views expressed in this publication are those of the authors and not necessarily those of the NHS or the Department of Health.

\section{About the authors}

Harry Lei is an Undergraduate Medical Student in the Centre for Psychiatry, Imperial College, London, UK. Kirsten Barnicot is a Research Fellow in the Centre for Psychiatry, Imperial College, London, UK. Emily Maynard is a Project Officer at the College Centre for Quality Improvement, Royal College of Psychiatrists, London, UK. Angela Etherington is a Service User Advisor at the College Centre for Quality Improvement, Royal College of Psychiatrists, London, UK. Krysia Zalewska is a Project Manager at the College Centre for Quality Improvement, Royal College of Psychiatrists, London, UK. Alan Quirk is a Senior Project Manager at the College Centre for Quality Improvement, Royal College of Psychiatrists, London, UK. Rahil Sanatinia is a Research Fellow in the Centre for Psychiatry, Imperial College, London, UK. Stephen J. Cooper is a Clinical Advisor at the College Centre for Quality Improvement, Royal College of Psychiatrists, London, UK. Mike J. Crawford is Director of the College Centre for Quality Improvement, Royal College of Psychiatrists, London, UK. 


\section{References}

1 Jethwa K, Galappathie N. Community treatment orders. BMJ 2008; 337: a613.

2 Geller JL. The last half-century of psychiatric services as reflected in psychiatric services. Psychiatr Serv 2000; 51(1): 41-67.

3 Parliament of the United Kingdom. Mental Health Act. W.J. Sharp, Controller and Chief Executive of Her Majesty's Stationery Office and Queen's Printer of Acts of Parliament, 1983.

4 Gibbs A, Dawson J, Ansley C, Mullen R. How patients in New Zealand view community treatment orders. J Ment Heal 2005; 14(4): 357-68.

5 Xiao J, Preston NJ, Kisely S. What determines compulsory community treatment? A logistic regression analysis using linked mental health and offender databases. Aust New Zeal J Psychiatry 2004; 38 (8): 613-8.

6 Corring D, O'Reilly R, Sommerdyk C. A systematic review of the views and experiences of subjects of community treatment orders. Int J Law Psychiatry 2017; 52: 74-80

7 Taylor M. Community treatment orders and their use in the UK. Adv Psychiatr Treat 2010; 16(04): 260-2.

8 Trevithick L, Carlile J, Nodiyal S, Keown P. Community treatment orders: an analysis of the first five years of use in England. $\mathrm{Br} J$ Psychiatry 2018; 212(03): 175-9.

9 Collinson D. Inpatients Formally Detained in Hospitals Under the Mental Health Act 1983, and Patients Subject to Supervised Community Treatment. NHS Digital, 2016.

10 Bhui K, Stansfeld S, Hull S, Priebe S, Mole F, Feder G. Ethnic variations in pathways to and use of specialist mental health services in the UK. Systematic review. Br J Psychiatry 2003; 182: 105-16.

11 Lawton Smith S. Briefing Paper 2 - Supervised Community Treatment Mental Health Alliance, 2010.

12 Patel MX, Matonhodze J, Baig MK, Gilleen J, Boydell J, Holloway F, et al. Increased use of antipsychotic long-acting injections with community treatment orders. Ther Adv Psychopharmacol 2011; 1(2): 37-45.

13 NHS Digital. Mental Health Act Statistics - Annual Figures: 2016-17, Experimental Statistics. NJS Digital, 2017.

14 Lawlor C, Johnson S, Cole L, Howard LM. Ethnic variations in pathways to acute care and compulsory detention for women experiencing a mental health crisis. Int J Soc Psychiatry 2012; 58(1): 3-15.

15 Singh SP, Burns T, Tyrer P, Islam Z, Parsons H, Crawford MJ. Ethnicity as a predictor of detention under the Mental Health Act. Psychol Med 2014; 44(05): 997-1004

16 Canvin K, Rugkåsa J, Sinclair J, Burns T. Patient, psychiatrist and family carer experiences of community treatment orders: qualitative study. Soc Psychiatry Psychiatr Epidemiol 2014; 49(12): 1873-82.

17 Burns $T$, Rugkåsa J, Molodynski A Dawson J, Yeeles K Vazquez-Montes $M$, et al. Community treatment orders for patients with psychosis (OCTET): a randomised controlled trial. Lancet 2013; 381(9878): 1627-33.

18 Maughan D, Molodynski A, Rugkåsa J, Burns T. A systematic review of the effect of community treatment orders on service use. Soc Psychiatry Psychiatr Epidemiol 2014; 49(4): 651-63.
19 Molodynski A, Rugkasa J, Burns T Coercion and compulsion in community mental health care. Br Med Bull 2010; 95(1): 105-19.

20 Royal College of Psychiatrists. Report of the National Audit of Schizophrenia (NAS) 2012. RCPsych, 2012.

21 Royal College of Psychiatrists. What is the National Clinical Audit of Psychosis (NCAP)? RCPsych, 2017.

22 National Clinical Audit of Psychosis. Core Audit Implementation Guide for Local NCAP Audit Leads. NCAP, 2017

23 Wing JK, Curtis RH, Beevor AS. Glossary for HoNOS Score Sheet. Royal College of Psychiatrists, 1996.

24 National Institute for Health and Care Excellence. BNF. NICE, 2018 (https://bnf.nice.org.uk).

25 SPSS. IBM SPSS Statistics Version 21. International Business Machines Corp., 2012

26 StataCorp. Stata Statistical Software: Release 14. StataCorp LP, 2015.

27 Churchill R, Owen G, Singh S, Hotopf M. International Experiences of using Community Treatment Orders. Department of Health, 2007.

28 Zammit S, Moore THM, Lingford-Hughes A, Barnes TRE, Jones PB, Burke $M$, et al. Effects of cannabis use on outcomes of psychotic disorders: systematic review. Br J Psychiatry 2008; 193(05): 357-63.

29 Dixon L. Dual diagnosis of substance abuse in schizophrenia: prevalence and impact on outcomes. Schizophr Res 1999; 35(Suppl): S93-100.

30 Bora E, Yucel M, Pantelis C. Cognitive functioning in schizophrenia, schizoaffective disorder and affective psychoses: meta-analytic study. Br J Psychiatry 2009; 195(06): 475-82.

31 DeRidder R, Molodynski A, Manning C, McCusker P, Rugkåsa J. Community treatment orders in the UK 5 years on: a repeat national survey of psychiatrists. BJPsych Bull 2016; 40(03): 119-23.

32 Romans S, Dawson J, Mullen R, Gibbs A. How mental health clinicians view community treatment orders: a National New Zealand Survey. Aust New Zeal J Psychiatry 2004; 38(10): 836-41.

33 Brooks R. The reliability and validity of the health of the nation outcome scales: validation in relation to patient derived measures. Aust New Zeal I Psychiatry 2000; 34(3): 504-11.

34 Pirkis JE, Burgess PM, Kirk PK, Dodson S, Coombs TJ, Williamson MK. A review of the psychometric properties of the Health of the Nation Outcome Scales (HoNOS) family of measures. Health Qual Life Outcomes 2005; 3(1): 76

35 Andreas S, Harries-Hedder K, Schwenk W, Hausberg M, Koch U, Schulz $\mathrm{H}$. Is the Health of the Nation Outcome Scales appropriate for the assessment of symptom severity in patients with substance-related disorders? J Subst Abuse Treat 2010; 39(1): 32-40.

36 National Institute for Health and Care Excellence. Psychosis and Schizophrenia in Adults: Prevention and Management Clinical Guideline 178. NICE, 2014.

37 Geller J. Community treatment orders for patients with psychosis Lancet 2013; 382(9891): 502

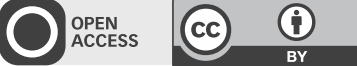

